research shoud focus upon these possible explanations.

\section{REFERENCES}

AVANT, L L \& BEVAN, W. Recognition of a stimulus class member after training with varied numbers of cases per elass. Journal of General Psychology, 1968, 78 . 241-246.

BEVAN, W. \& DUKES, W. F. Stimulus-variation and recall: The role of belongingness. American Joumal of Psy chology, 1967, 80, 309-312.

BEVAN, W., DUKES, W. F., \& AVANT, L. $L$. The effect of variation in specific stimuli on memory for their superordinates. American Joumal of Superordinates. American Jo

BOUSFIELD, W. A., \& COHEN, B. H. The occurrence of clustering in the recall of randomly arranged words of different frequencies of usage. Journal of General Psychology, 1955, 52, 83-95.

CROWDER, R. G., \& HOENIG, Y.J. Intertrial competition and the prefix effect. Journal of Experimental Psychology, 1969, 79, 368-370.

DAVES, W. F. \& ADKINS, M. Stimulus variation and free recall: A confirmation American Journal of Psychology, 1969, 82, $122-124$
DAVES. H. F. \& RINN. R. C. The variety effect in free recall as a function of pre-recall activity. Psychonomic Science, $1971,22,226-227$

JAHNKE, J. C. The Ranschburg effect. Psychological Review, 1969, 76, 592-605. McCARSON, C., \& DAVES, IV. F. Free recall of object names in pre-school children as a function of intracategory children as a function of intracategory variation.

TULVING, E. Theoretical issues in free recall. In $T$. R. Dixon and D. L. Horton (Eds.), Verbal behavior and general behavior theory. Englewood Cliffs, N.J: Prentice-Hall, 1968. Pp. 2-36.

$$
\text { NOTE }
$$

1. Daves \& Rinn (1971); and Daves, IV. F. \& Rinn, R. C. The effect of stimulus duration and interstimulus interval on the superiority in recall of varied over repeated categories, in preparation. Both of the above studies show that the variety effect described in the present experiment occurs regardless of which particular categories of objects are repeated, as opposed to varied. Therefore, that control was not included in the present experiment, but rather an attempt was made to assign categories to the $R$ or the $V$ group so that overall recall would be approximately equal.

\title{
Retrieval time in forward and backward recall*
}

\section{TERRY R. ANDERS and TIMOTHY D. LILLYQUIST $†$}

Harvard Medical School, Boston, Mass. 02114

The present experiment was designed to compare the rates of forward and backward digit recall. The results show that recall was faster in forward order than in backward order. This finding is consistent with the hypothesis that information can be retrieved from short-term memory only in the same order in which it is stored.

Retrieval from short-term memory has been assumed by some to be unidirectional, i.e., information can be retrieved only in the same order in which it was stored (Broadbent, 1958; Conrad, 1965; Wickelgren, 1966; Yntema \& Trask, 1963). Evidence frequently cited in support of this contention is the superiority of the forward memory span over the backward span. It is maintained that the forward span is longer because information is retrieved from memory in the same order in which it is to be reported, while backward recall requires that the retrieved information be reordered before it can be reported. Conrad (1965) suggested that this transformation is accomplished by a succession of rapid to-and-fro scans. That is, each item reported in backward order is preceded by S's scanning forward through the list in memory to locate and retrieve it. This

*This research was supported by U.S. Public Health Service Grant No. MH-17110 and by Social Rehabilitation Service Grant No. RD-2685-M

+ Now at Northeastern University. Boston, Mass. 02115. additional operation requires time, over the course of which some forgetting would be expected to occur. As a result, the backward memory span is normally shorter than the forward span.

This account of the differences between the forward and backward memory spans predicts that, in addition to the forward span being longer, items recalled in forward order should also be reported at a faster rate. The forward memory span has been shown many times to be longer than the backward span. The rate at which the items are reported has not, however, previously been investigated. The present experiment was designed to compare the rates at which items are recalled under these two conditions and to further explore the underlying retrieval processes.

$$
\text { METHOD }
$$

Ten females recruited from Massachusetts General Hospital School of Nursing served as paid volunteers. Testing was divided into two sessions, one for the immediate recall of 76 lists of random digits in the forward order and one for the immediate recall of 76 similar lists in backward order. The sessions were separated by at least $24 \mathrm{~h}$. Half of the Ss received the forward order first, and half received the backward order first. Digit lists were also counterbalanced to insure that each appeared equally often under each order condition.

At the beginning of each session, the Ss were instructed that on each trial they would be read a short list of random digits to be recalled in either the forward or backward order, depending on the condition to which they had been assigned. Following the last digit of the list, a buzzer signaled them to begin recalling the digits. They were further instructed to recall the digits as fast as possible without sacrificing accuracy. The digit lists were read in a monotone at a $1 / \mathrm{sec}$ rate. The buzzer was sounded about $I$ sec after the last digit had been given. Several seconds following S's recall, she was cued to listen, and the next trial began. In all sessions, a 5 -min rest period was given between Trials 38 and 39 .

Each session began with the recall of a three-digit list. The list presented on each trial thereafter was one digit longer than the preceding one until S made an incorrect recall. An incorrectly recalled list was followed by a list one digit shorter in length. Each S's span was thereby determined by a method of adjustment.

All trials were recorded on a Roberts Model 1719 stereo tape recorder at $7 \frac{1}{2}$ ips. To measure the rate of recall, the completed tapes were played at $33 / 4$ ips into a Grass Model 5C polygraph with a fast paper speed of $7.2 \mathrm{~cm} / \mathrm{sec}$. This procedure allowed easy discrimination between responses and interresponse pauses. These two variables will be treated separately below. Only correctly recalled lists were included in the analyses. In addition, the first 10 trials under each condition were considered as practice and excluded.

\section{RESULTS}

The main findings are summarized in Fig. 1. The lower curve depicts the cumulative pause time between responses at each serial position in forward recall. An average pause of $676 \mathrm{msec}$ preceded the first response, and one of $131 \mathrm{msec}$ preceded each additional response thereafter. Each digit required an average of $197 \mathrm{msec}$ to be spoken. The equation of the line of best fit of the cumulative pause time was $\mathrm{RT}=.510+.131 \mathrm{SP}$, where SP indicates serial position in recall and RT denotes cumulative time between responses. The coefficient of determination was .99 . The upper curve in Fig. 1 shows the equivalent data for backward recall. Under this condition, the first digit was preceded by a pause of $1,294 \mathrm{msec}$ and each 
digit thereafter by one of 385 msec. An average time of $259 \mathrm{msec}$ was required to speak each digit. The equation of the line of best fit was RT $=.741+.385 \mathrm{SP}$, and the coefficient of determination was .98 .

Separate analyses of variance were performed on the slopes and intercepts of the regression lines fitted to each $S$ 's data under the two conditions. The results of these analyses show that the first digit was reported sooner $(p<.05)$ and that the remaining digits were reported at a faster rate $(\mathrm{p}<.001)$ forward than backward, 3 items/sec as compared with 1.5 items/sec. Neither the slope nor the intercept varied with list length under either order condition. As expected, however, the average length of lists recalled in the forward order (7.2 digits) exceeded that of lists recalled in the backward order (5.6 ditis), and this difference was statistically significant $(p<.05)$. The length of time required to say the digits was longer for the backward order than for the forward order ( $p<.01)$, reflecting, perhaps, the Ss' habit of drawing out sounds to fill delays in speech and maintain the continuity of their responses.

\section{DISCUSSION}

The present findings clearly show that forward recall is faster than backward recall. According to Conrad, backward recall is slower because the order of retrieval and report do not coincide as they do in forward recall. Consequently, the slower pace reflects the additional time to transform the order of items for the backward report. The assumed transformation is a succession of rapid to-and-fro scans, i.e., each item recalled in backward order is preceded by scanning the memorized list in the forward order to retrieve it.

The retrieval mechanism underlying forward recall seems to be a serial memory search of the sort described by Sternberg (1967), in that recall was evenly paced at a rate of 3 items $/ \mathrm{sec}$. Sternberg's Ss had to scan a memorized list and then report only a single item, while the present Ss were required to report every item in a list. Their respective rates of progress through the memorized material were, however, about the same. Moreover, Weber \& Blagowsky (1970) compared the rates of silent and overt memory scanning and found no differences between them. Under both conditions retrieval was accomplished via a serial search again proceeding at a rate of 3 items/sec. These apparent similarities between implicit and explicit memory scanning support Conrad's earlier contention that forward recall is simply a readout of information as it is retrieved from short-term memory.
The present findings are also in general agreement with Conrad's characterization of the retrieval process underlying backward recall. More important, perhaps, it agrees with the Ss' introspections of how they performed the task. They all

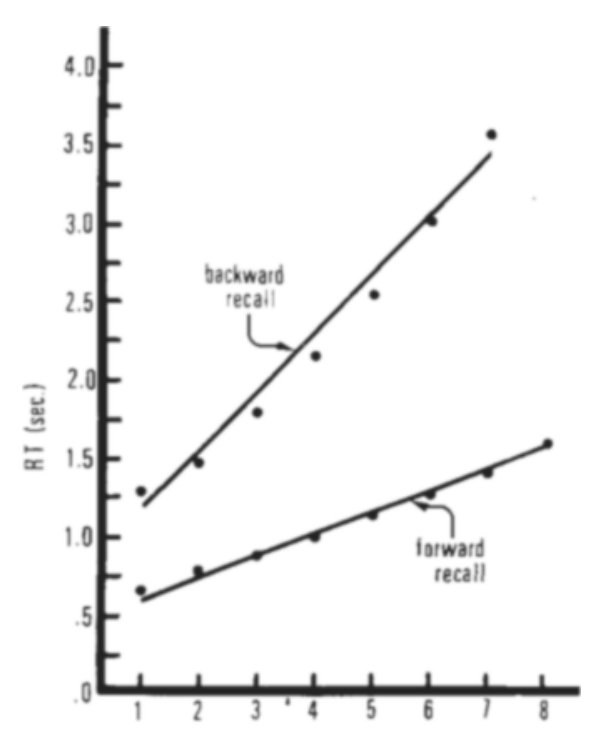

SERIAL POSITION

Fig. 1. Mean cumulative pause time at each serial position in forward and backward recall.

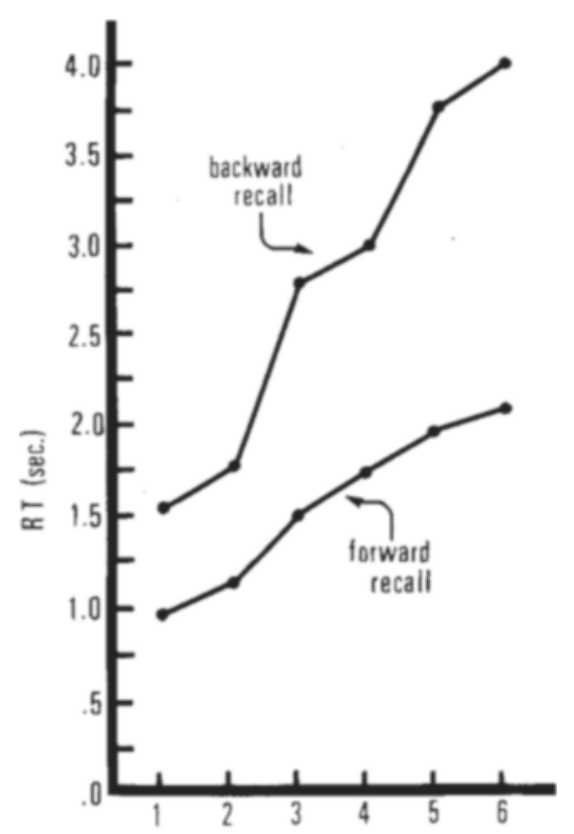

SERIAL POSITICN

Fig. 2. Mean cumulative pause time at each serial position for one $S$ who reported organizing incoming digits into groups of two. reported that backward reall wat not simply a readout of items in the order of retrieval as was forward recall. Instead, Ss typically reported retrieving the last two or three items of the list as a group, reading them out in backward order, dipping back into memory, retrieving the next group of two or three items, reading them out in backward order, and so forth until recall was completed. They also felt that they had direct access to the groups in memory

The contents of the groups were determined by the strategy $S$ s used to organize the list for storage. For example, one $S$ reported that she always organized the digits in groups of two while they were being presented. Her backward recall latencies (see Fig. 2) show that she also recalled the items in groups of two, i.e., the pauses between Items 1 and 2,3 and 4 , and 5 and 6 were always much shorter than those between Intergroup Items 2 and 3 and 4 and 5. Most Ss used less systematic strategies of organizing the lists, and group size varied both within and between lists. Averaging across Ss and across triais cancels the effects of grouping and produces a smooth linear function. Groups of two and three items each are, however, evident in the data for individual trials. Similar groupings of items were not evident when recall was in the forward order.

The long pauses between grouped items in backward recall are the distinguishing characteristic between the two recall conditions. They account for the slower rate of backward recall. The $\mathrm{Ss}$ associated these pauses with the retrieval of the next group of items for recall. As a result, it appears certain that most, if not all, of the extra time required for backward recall reflects the retrieval of groups of items, not of individual items as such. This added step is evidently necessary because items cannot be retrieved directly in backward order.

\section{REFERENCES}

BROADBENT, D. E. Perception and communication. London: Pergamon Press, 1958.

CONRAD, R. Order error in immediate recall of sequences. Joumal of Verbal Learning \& Verbal Behavior, 1965, 4, 161-169.

STERNBERG, $S$. Retrieval of contextual information from memory. Psy chonomic Science, 1967, 8, 55-56.

WEBER, R. J., \& BLAGOWSKY, J. Metered memory search with implicit and explicit scanning. Journal of Experimental Psychology, 1970, 84, 343-348.

WISKELGREN, W. A. Phonemic similarity and interference in short-term memory for single letters. Journal of Ex perimental Psychology, 1966, 71, 396-404.

YNTEMA. D. B., \& TRASK, F. P. Recall as a search process. Journal of Verbal Learning \& Verbal Behavior, 1963, 2, 65-74. 